\title{
Expanded eggshell procedure combined with closing-opening technique (a modified vertebral column resection) for the treatment of thoracic and thoracolumbar angular kyphosis
}

\author{
Xinyu Liu, MD, Suomao Yuan, MD, Yonghao Tian, MD, Lianlei Wang, MS, Yanping Zheng, MD, and \\ Jianmin Li, MD
}

Department of Orthopedic Surgery, Qilu Hospital of Shandong University, Jinan, Shandong, People's Republic of China

OBJECT The purpose of this study was to determine the efficacy of a modified vertebral column resection for the treatment of thoracolumbar angular kyphosis.

METHODS A total of 13 patients (8 male, 5 female) with thoracolumbar kyphosis (kyphotic angle $>60^{\circ}$ ) were included in this study (Group A). There were 3 patients with failure of spinal formation (Type 1 deformity), 6 patients with old thoracic or lumbar compression fracture, and 4 patients with old spinal tuberculosis (including 1 case of T3-5 vertebral malunion). The average preoperative kyphotic angle was $67.3^{\circ}$ (range $62^{\circ}-75^{\circ}$ ). Each patient underwent an expanded eggshell procedure combined with the closing-opening technique for the treatment of thoracolumbar angular kyphosis. Sixteen patients who were previously treated with a closing-opening wedge osteotomy in the same spine classification group (kyphotic angle $>60^{\circ}$ ) were used as a control group (Group B).

RESULTS In Group A, the average ( \pm SD) operative time was $400 \pm 60$ minutes, and the average blood loss was $960 \pm$ $120 \mathrm{ml}$. There were no surgery-related complications observed during or after the operations. The average local kyphotic angle was $20.3^{\circ}$ (range $18^{\circ}-24.5^{\circ}$ ), and the average correction rate was $68.7 \%$. In Group B, the average operative time was $470 \pm 90$ minutes, and the average blood loss was $2600 \pm 1600 \mathrm{ml}$ (range 1200-8200 ml). There were segmental vessels and spinal canal venous plexus injury in 1 case, spinal cord injury in 1 case, dural tearing in 2 cases, pleural rupture in 2 cases, and hemothorax and pneumothorax in 1 case. Each patient had more than 2 years of follow-up. At the latest follow-up examination, the average regional kyphotic angle was $19.9^{\circ} \pm 9.1^{\circ}$ (range $19^{\circ}-34^{\circ}$ ), and there was no significant loss of correction ( $p>0.05$ ). There was greater blood loss and a higher complication rate in Group B than in Group A ( $p<0.05)$.

CONCLUSIONS An expanded eggshell procedure combined with the closing-opening technique for the treatment of thoracolumbar angular kyphosis resulted in significant reduction of the kyphotic angle, few complications, and good follow-up results. However, a larger series of patients and long-term follow-up results is still required to verify the effectiveness and safety of this method.

http://thejns.org/doi/abs/10.3171/2014.11.SPINE14710

KEY WORDS kyphosis; eggshell; closing-opening procedure; correction; technique; thoracic spine

$\mathrm{T}$ Horacolumbar kyphosis is a clinically common spinal deformity caused by hemivertebrae (Type 1 deformity), specific and nonspecific spine infection, trauma, and iatrogenic kyphosis, among other causes. Severe thoracic and thoracolumbar kyphosis is usually associated with severe low-back pain or severe neurological dysfunction. The main surgical methods for kyphosis correction include Smith-Petersen osteotomy (SPO), pedicle subtraction osteotomy (PSO), closing-opening wedge osteotomy (COWO), vertebral column resection (VCR), and vertebral column decancellation.

In 1945, Smith-Petersen et al. ${ }^{8}$ first reported the clini-

ABBREVIATIONS ASIA = American Spinal Injury Association; COWO = closing-opening wedge osteotomy; LL = lumbar lordosis; $\mathrm{PI}=$ pelvic incidence; PSO = pedicle subtraction osteotomy; PT = pelvic tilt; PVCR = posterior vertebral column resection; RKA = regional kyphotic angle; SPO = Smith-Petersen osteotomy; SVA = sagittal vertical axis; TK = thoracic kyphosis; VAS = visual analog scale; VCR = vertebral column resection.

SUBMITTED July 18, 2014. ACCEPTED November 4, 2014

INCLUDE WHEN CITING Published online April 24, 2015; DOI: 10.3171/2014.11.SPINE14710.

DISCLOSURE The authors report no conflict of interest concerning the materials or methods used in this study or the findings specified in this paper. The following grants funded this study: ZR2009CQ020 from the Shandong Province Natural Science Foundation, China, and 81277024 from the Natural Science Foundation of China. 
cal efficacy of the SPO for the treatment of ankylosing spondylitis, and subsequently, many scholars performed a multisegmental SPO for kyphosis treatment. The SPO is relatively safe and has a low level of technical difficulty, but it has a poor correction effect for sagittal deformity and cannot be performed to correct large kyphotic angles. In 1985, Thomasen ${ }^{11}$ first reported PSO. The previous year, Heining ${ }^{3}$ described an "eggshell" osteotomy-a transpedicular decancellation closed-wedge osteotomyas a variant of the PSO. ${ }^{1}$ Compared with the SPO, the PSO can achieve the purpose of 3-column osteotomy, which not only promotes bone healing after shortening of the spine but also effectively avoids stretching the major vessels and viscera anterior to the spine, which can be caused by opening of the vertebrae after SPO. Single-segment PSO can correct $30^{\circ}-40^{\circ}$ of kyphosis, but for a kyphotic angle of $>60^{\circ}$, it is difficult to achieve a good correction effect using a single-segment PSO. ${ }^{9}$ To effectively improve kyphosis correction effects, Kawahara et al. ${ }^{4}$ first reported the closing-opening technique. Based on the pedicle wedge osteotomy, opening in the front and closing at the back effectively improved the kyphosis correction rate. In their 7 cases of kyphosis, the average preoperative angle of $68^{\circ}$ was reduced to a postoperative angle of $16^{\circ}$ with a correction rate of $73.1 \%$. The VCR is also an effective way to correct such malformations. In 1922, MacLennan first reported on VCR via both anterior and posterior approaches. ${ }^{1}$ In 2005, Suk et al. ${ }^{10}$ reported on a single posterior VCR (PVCR) technique. The technique can effectively correct lateral and rotational deformity of the spine. Hamzaoglu et al. ${ }^{2}$ reported that VCR resulted in a sagittal correction rate of $72 \%$. Lenke et al. ${ }^{5}$ reported that VCR resulted in a correction rate of 58\% for kyphosis. However, PVCR is usually associated with surgical trauma, huge blood loss, and spinal cord injury, which are the most serious complications. Suk et al. reported that PVCR had a surgical complication rate of $34.3 \%$ and neurological injury rate of $17.1 \%$. Lenke et al. reported that the overall rate of complications was approximately $40 \%$, and within that group, $11.4 \%$ of the patients had neurological damage. To further improve the efficacy of surgery and reduce the number of complications, Wang and Lenke ${ }^{12}$ used vertebral column decancellation to treat 45 cases of kyphosis and kyphoscoliosis; in 16 cases the average correction angle was $82.2^{\circ}$ (range $61^{\circ}-124^{\circ}$ ). The overall complication rate was $17.8 \%, 4 \%$ of which included neurological damage.

In this study, we report the clinical efficacy of an expanded eggshell procedure combined with the closingopening technique for the treatment of thoracic and thoracolumbar kyphosis.

\section{Methods}

\section{Patient Population}

A total of 13 patients (8 male, 5 female; average age 33.5 years [range 15-47 years]) with thoracolumbar kyphosis (kyphotic angle $>60^{\circ}$ ) were included in this study (Group A). There were 3 patients with failure of spinal formation (Type 1 deformity), 6 patients with old thoracic or lumbar compression fracture, and 4 patients with old spinal tuberculosis (including 1 case of T3-5 vertebral malunion). The vertebral kyphosis was located in T3-5 (n $=1), T 7-8(\mathrm{n}=1)$, T8-9 $(\mathrm{n}=1), \mathrm{T} 11-12(\mathrm{n}=1), \mathrm{T}-12(\mathrm{n}=$ $4)$, or L-1 $(n=5)$.

A $10-\mathrm{cm}$ visual analog scale (VAS) was used to assess back pain (0 indicates no pain/numbness, and 10 represents the worst pain/numbness). The mean ( \pm SD) preoperative VAS score was $6.1 \pm 2.3$. Ten patients with a T11-L1 lesion had severe back pain (VAS score $\geq 7$ ). The remaining 3 patients, with chronic spinal tuberculosis kyphosis, had obvious associated neurological deficits, and their preoperative American Spinal Injury Association (ASIA) Impairment Scale grade was $C$ in 1 case and D in 2 cases. The characteristics of the patients are summarized in Table 1. Each patient underwent an expanded eggshell procedure combined with the closing-opening technique for treatment.

Sixteen patients ( 6 male, 10 female; average age 26.5 years [range 13-34 years]) who were previously treated with the COWO in the same spine classification group (kyphotic angle $>60^{\circ}$ ) were used as a control group (Group B): 3 patients with failure of spinal formation (Type 1 deformity), 7 patients with old thoracic or lumbar compression fracture, and 6 patients with old spinal tuberculosis. The vertebral kyphosis was located at T-7 $(\mathrm{n}=2), \mathrm{T}-9(\mathrm{n}=$ $1)$, T-11 ( $=2)$, T-12 $(n=7)$, or L-1 $(n=4)$. The mean preoperative VAS score for back pain was $6.8 \pm 1.4$. Fourteen patients with a lesion located at T9-L1 had severe back pain (VAS score $\geq 7$ ), and the remaining 2 patients ( 1 with Type 1 deformity and 1 with tuberculosis and kyphosis) had associated neurological disorders, with preoperative ASIA Impairment Scale grades of C in one patient and D in the other.

\section{Radiographic Measurements}

Each patient underwent full-length standing spine radiography that included a lateral view with visualization from at least the C-7 vertebral body to the pelvis. Radiographic measurements were made by using a standard technique and included regional kyphotic angle (RKA), C7-S1 sagittal vertical axis (SVA), pelvic incidence (PI), pelvic tilt (PT), sacral slope, lumbar lordosis (LL), and thoracic kyphosis (TK). Patients were classified as having positive global sagittal malalignment if their C7-S1 SVA was $\geq 5$ $\mathrm{cm}$. The correction rate was calculated as [(preoperative RKA - postoperative RKA)/preoperative RKA] × $100 \%$.

CT scanning was used for preoperative deformity assessment and to evaluate bone fusion during follow-up. Preoperative MRI was used to exclude intraspinal canal diseases and to evaluate compression of the spinal cord.

\section{Surgical Procedure}

In Groups A and B, general anesthesia, neuromonitoring, and autologous blood transfusion were used during the operations.

For each patient in Group A, using the midline posterior approach, we detached the paravertebral muscles from the spinous processes and lamina to expose the surgical levels. Pedicle screws were inserted in the upper and lower 2-3 segments of the proposed osteotomy site. Then, the lamina transverse processes and the facet joint at the 
TABLE 1. Demographics of patients who underwent an expanded eggshell procedure combined with the closing-opening technique (Group A)

\begin{tabular}{ccllccc}
\hline $\begin{array}{c}\text { Patient } \\
\text { No. }\end{array}$ & $\begin{array}{c}\text { Age (yrs), } \\
\text { Sex }\end{array}$ & \multicolumn{1}{c}{ Preop Diagnosis } & $\begin{array}{c}\text { Affected } \\
\text { Level }\end{array}$ & $\begin{array}{c}\text { Preop } \\
\text { RKA }\left(^{\circ}\right)\end{array}$ & $\begin{array}{c}\text { Back Pain } \\
\text { VAS Score }\end{array}$ & $\begin{array}{c}\text { ASIA Impairment } \\
\text { Scale Grade }\end{array}$ \\
\hline 1 & $39, \mathrm{M}$ & Old spinal tuberculosis & T7-8 & 65 & 0 & $\mathrm{D}$ \\
\hline 2 & $19, \mathrm{M}$ & Type 1 deformity & $\mathrm{T}-12$ & 60 & 8 & $\mathrm{E}$ \\
\hline 3 & $30, \mathrm{~F}$ & Old spinal tuberculosis & $\mathrm{T} 3-5$ & 62 & 0 & $\mathrm{C}$ \\
\hline 4 & $37, \mathrm{M}$ & Old spinal tuberculosis & $\mathrm{T}-9-9$ & 67 & 0 & $\mathrm{D}$ \\
\hline 5 & $15, \mathrm{~F}$ & Type 1 deformity & $\mathrm{T} 11-12$ & 64 & 9 & $\mathrm{E}$ \\
\hline 6 & $47, \mathrm{~F}$ & Old compression fracture & $\mathrm{T}-12$ & 75 & 7 & $\mathrm{E}$ \\
\hline 7 & $20, \mathrm{~F}$ & Type 1 deformity & $\mathrm{L}-1$ & 65 & 9 & $\mathrm{E}$ \\
\hline 8 & $43, \mathrm{M}$ & Old compression fracture & $\mathrm{L}-1$ & 69 & 8 & $\mathrm{E}$ \\
\hline 9 & $40, \mathrm{M}$ & Old compression fracture & $\mathrm{T}-12$ & 68 & 7 & $\mathrm{E}$ \\
\hline 10 & $39, \mathrm{M}$ & Old spinal tuberculosis & $\mathrm{L}-1$ & 70 & 8 & $\mathrm{E}$ \\
\hline 11 & $32, \mathrm{M}$ & Old compression fracture & $\mathrm{T}-12$ & 67 & 7 & $\mathrm{E}$ \\
\hline 12 & $38, \mathrm{M}$ & Old compression fracture & $\mathrm{L}-1$ & 72 & 8 & $\mathrm{E}$ \\
\hline 13 & $36, \mathrm{~F}$ & Old compression fracture & $\mathrm{L}-1$ & 68 & 8 & $\mathrm{E}$ \\
\hline
\end{tabular}

resection level were removed. To reduce the spinal cord injury caused by shrinkage of the spinal cord, the laminae below and above the osteotomy level were also removed. Then, the left pedicle at the osteotomy level was identified and decancellated using a high-speed drill and a curette. After that, the cortical bone of the pedicle was removed, which enabled access to the vertebral body and protection of the dura and nerve roots. By using the eggshell technique, decancellation of the vertebral body was subsequently performed with a drill and a curette on the left side. The cortical bone on the left side of the vertebral body was burred away gradually, and part of the rib adjacent to the transverse process and vertebral body was also drilled away to create a sufficient space for placing titanium mesh. If the osteotomy site was at or above T-12, the nerve root at this level was ligated to facilitate the osteotomy. A temporary fixing rod was placed to maintain the stability of the spine. Similar procedures were performed on the right side. Because we planned to place titanium mesh from the left side, only decancellation of the vertebral body was performed. Cortical bone from the anterior and right side of the vertebral body and the rib were preserved (Fig. 1 upper). The discs and endplates above and below the osteotomy were then removed from both sides.

Finally, the portion of the vertebral body underlying the anterior spinal canal was removed using a bur and an L-shaped posterior wall impactor to collapse this bone into the cavity. The titanium mesh filled with autograft was placed through the left side. We preferred to place the mesh on one side, not at the midline of the coronal section, so that we could implant more autograft from the other side. The precurved rods, sized at an appropriate length, were placed and kyphosis was corrected using the closing-opening technique, which was first described by Kawahara et al. ${ }^{4}$ After deformity correction, a large amount of autograft and allograft bone was implanted from the right side (Fig. 2).

In Group B, each patient underwent a COWO for kyphosis correction. ${ }^{4}$ The exposure, insertion of pedicle screws, and laminectomy levels were identical to those in Group A. After that, ribs at the affected level were transected 3-4 $\mathrm{cm}$ lateral to the costotransverse joint, and the pleura was bluntly separated from the vertebra. The rib heads and the

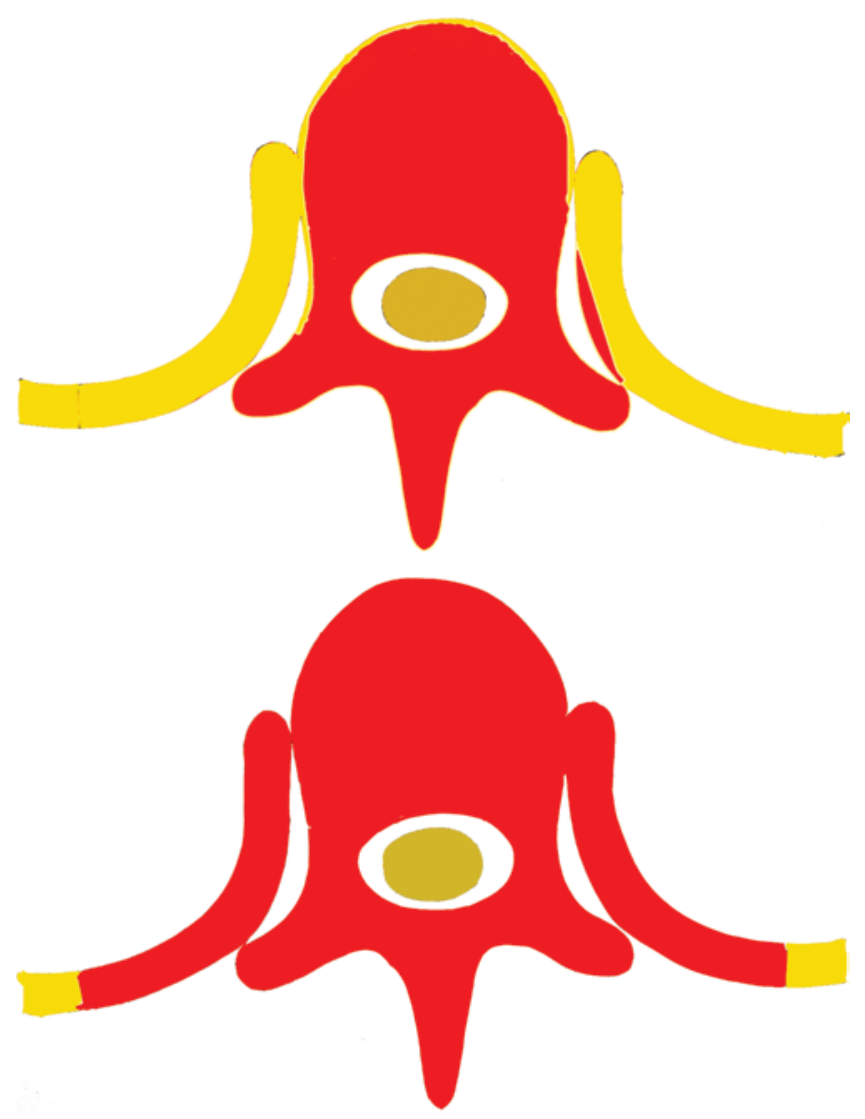

FIG. 1. Schematic of expanded eggshell procedure combined with the closing-opening technique (upper) and the VCR procedure (lower). Red represents the resected part of the affected vertebra. Figure is available in color online only. 


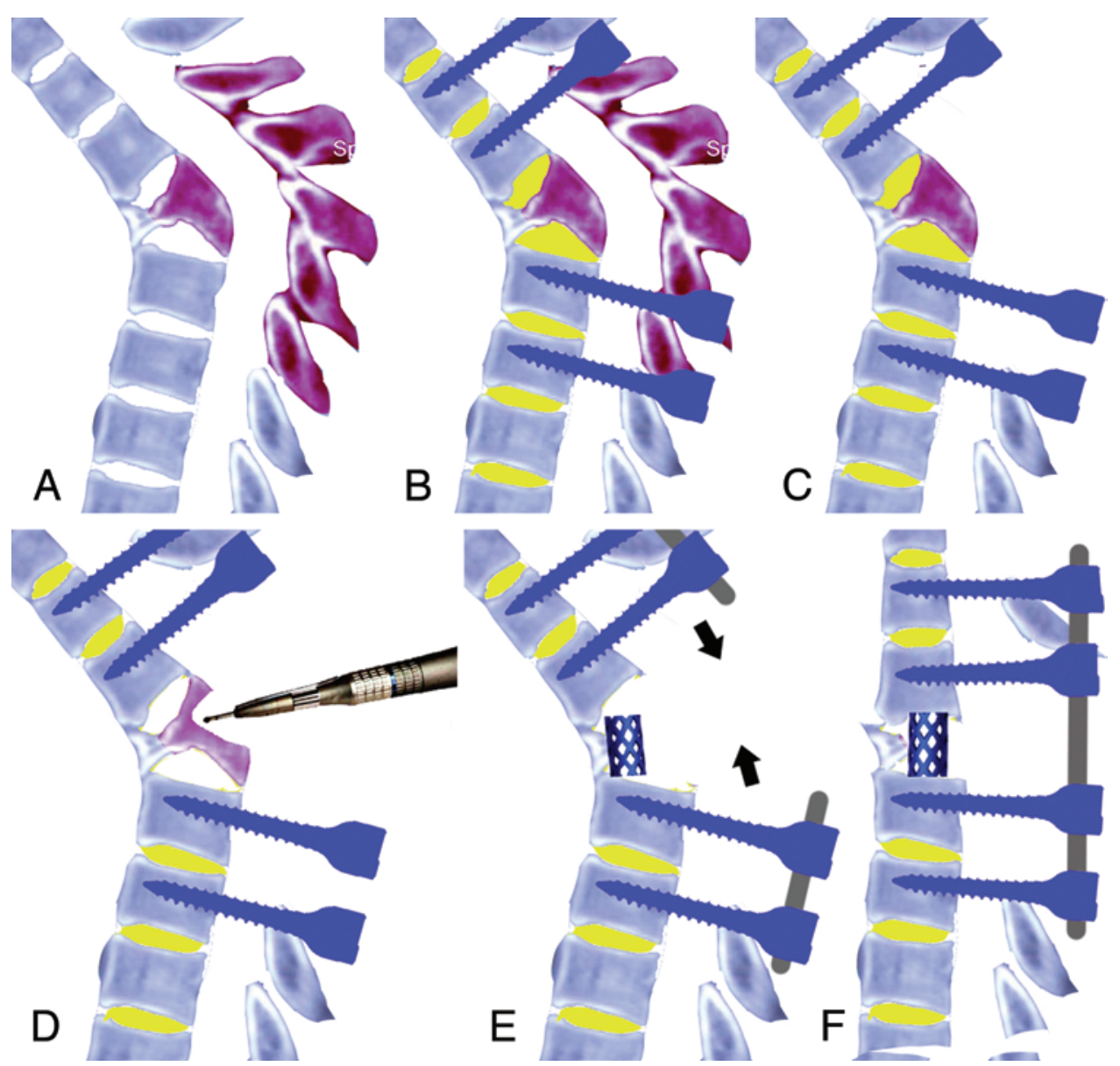

FIG. 2. Surgical procedure. After exposure of the corresponding spinous process (Sp), lamina, and facet (A), pedicle screws were placed (B). An expanded eggshell procedure was then performed, and the curvature was corrected using the closing-opening technique (C-F). Figure is available in color online only.

transverse processes were excised. The pedicle for the osteotomy was identified, and blunt dissection was used anteriorly on both sides through the plane between the pleura and the vertebral body. The vertebral body was removed in a wedge shape, and the posterior vertebral cortex was drilled out. Subsequently, the disc was removed (Fig. 1 lower). Two short rods (correction rods) were positioned. The first $30^{\circ}-35^{\circ}$ of kyphosis was corrected using the closing-wedge technique with the hinge of the anterior longitudinal ligament. Next, the hinge was moved posteriorly to the spinal cord, and the remainder of the requisite angle of osteotomy was corrected using the opening-wedge technique to avoid spinal cord deformation.

\section{Statistical Analysis}

The SPSS version 12.0 software package (SPSS, Inc.) was used for statistical analysis. The Student t-test and the chi-square test were used to determine the statistical significance. The level of significance was set at a $p$ value of $<0.05$. Mean values are presented \pm SD .

\section{Results}

Demographics of the patients in Group A are shown in
Table 1. The preoperative and postoperative RKA, correction rate, LL, TK, SVA, PI, PT, back pain VAS score, operative time, blood loss, and complication rate are shown in Table 2.

In Group A, the RKA, LL, TK, SVA, PI, and back pain VAS score were significantly improved at the latest follow-up $(p<0.05)$. There were no segmental vessel or nerve injury, dural tearing, pleural rupture, hemothorax, or pneumothorax during or after the operation. Each patient underwent at least 2 years of follow-up (range 24-36 months, mean 29.6 months). At the latest follow-up, the mean RKA was $20.3^{\circ} \pm 2.5^{\circ}$ (range $19^{\circ}-23.3^{\circ}$ ), and there was no significant loss of correction ( $p>0.05)$. The condition of the 3 patients with a neurological deficit improved from ASIA Impairment Scale Grade C to D in 1 case or from $\mathrm{D}$ to $\mathrm{E}$ in 2 cases. Mean back pain VAS scores improved from $6.1 \pm 2.3$ to $2.1 \pm 1.9(\mathrm{p}<0.05)$. There was no loss of correction, loosening of internal fixation, or pseudarthrosis during the follow-up period (Fig. 3).

In Group B, the RKA, LL, TK, SVA, PI, and back pain VAS scores were significantly improved at the latest follow-up $(\mathrm{p}<0.05)$. One or two complications occurred in 6 cases $(37.5 \%)$. There were segmental vessels and spinal canal venous plexus injury in 1 case, spinal cord injury in 
TABLE 2. Preoperative and postoperative clinical results of our 2 study groups*

\begin{tabular}{|c|c|c|c|}
\hline Parameter & Group A & Group B & $p$ Value \\
\hline \multicolumn{4}{|l|}{ Preop } \\
\hline $\mathrm{RKA}\left({ }^{\circ}\right)$ & $67.3 \pm 7.1$ & $70.7 \pm 10.5$ & 0.35 \\
\hline $\operatorname{LL}\left({ }^{\circ}\right)$ & $24.6 \pm 14.3$ & $27.1 \pm 16.7$ & 0.11 \\
\hline $\mathrm{TK}\left({ }^{\circ}\right)$ & $40.2 \pm 11.0$ & $39.7 \pm 20.0$ & 0.83 \\
\hline SVA (cm) & $-2.1 \pm-2.4$ & $-4.0 \pm-1.2$ & 0.08 \\
\hline $\mathrm{PI}\left({ }^{\circ}\right)$ & $44.6 \pm 11.6$ & $48.0 \pm 12.0$ & 0.12 \\
\hline $\mathrm{PT}\left({ }^{\circ}\right)$ & $10.1 \pm 1.3$ & $9.5 \pm 1.7$ & 0.90 \\
\hline Back pain VAS score & $6.1 \pm 2.3$ & $6.8 \pm 1.4$ & 0.07 \\
\hline Operative time (mins) & $400 \pm 60$ & $470 \pm 90$ & 0.06 \\
\hline Blood loss (ml) & $960 \pm 120$ & $2600 \pm 1600$ & $0.00 \dagger$ \\
\hline Complication rate, \% (no.) & $0(0)$ & $37.5(6)$ & $0.00 \dagger$ \\
\hline \multicolumn{4}{|l|}{ Postop } \\
\hline $\operatorname{RKA}\left({ }^{\circ}\right)$ & $20.3 \pm 2.5$ & $19.9 \pm 9.1$ & 0.82 \\
\hline $\operatorname{LL}\left({ }^{\circ}\right)$ & $41.4 \pm 8.3$ & $44.0 \pm 4.5$ & 0.17 \\
\hline $\mathrm{TK}\left({ }^{\circ}\right)$ & $36.3 \pm 4.2$ & $33.2 \pm 5.1$ & 0.22 \\
\hline SVA (cm) & $-0.9 \pm-1.2$ & $-1.1 \pm-0.9$ & 0.59 \\
\hline $\mathrm{PI}\left({ }^{\circ}\right)$ & $46.5 \pm 12.4$ & $50.5 \pm 5.7$ & 0.64 \\
\hline $\mathrm{PT}\left({ }^{\circ}\right)$ & $12.3 \pm 2.5$ & $11.3 \pm 1.0$ & 0.78 \\
\hline Back pain VAS score & $2.1 \pm 1.9$ & $2.5 \pm 0.8$ & 0.11 \\
\hline Correction rate, $\%$ & 68.7 & 70.2 & 0.47 \\
\hline
\end{tabular}

* Values are expressed as the mean \pm SD or percentage (number). $\dagger p<0.05$.

1 case (ASIA Impairment Scale grade from $\mathrm{E}$ to $\mathrm{C}$ ), dural tearing in 2 cases, pleural rupture in 2 cases, and hemothorax and pneumothorax in 1 case. Each patient had undergone at least 2 years of follow-up (range 24-39 months, mean 30.2 months). At the latest follow-up, the mean RKA was $19.9^{\circ} \pm 9.1^{\circ}$ (range $\left.19^{\circ}-34^{\circ}\right)$, and there was no significant loss of correction ( $\mathrm{p}>0.05)$. The condition of 3 patients with a neurological deficit improved from ASIA Impairment Scale grade $\mathrm{C}$ to $\mathrm{D}$ in 2 cases (including 1 case caused by osteotomy) and from $\mathrm{D}$ to $\mathrm{E}$ in 1 case.

There were no significant differences in preoperative and postoperative RKA, PI, PT, LL, TK, SVA, surgical time, and correction rate between Groups A and B ( $p>$ 0.05 ). There was greater blood loss and a higher complication rate in Group B ( $<0.05)$. A solid fusion was achieved in 11 and 13 patients by the 6-month follow-up in Groups A and B, respectively, whereas in the other patients in Groups A and B fusion was achieved by the 1-year follow-up.

\section{Discussion}

According to the spinal osteotomy classification reported by Schwab et al., ${ }^{7}$ the osteotomy performed in our technique is classified as complete vertebral and disc resection (Grade 5) in 12 cases and multiple adjacent vertebral and disc resection (Grade 6) in 1 case (T3-5 vertebral malunion). Three-column osteotomy at the thoracic and thoracolumbar levels includes mainly the following steps: 1) removal of $3-5 \mathrm{~cm}$ of the medial rib; 2) wide laminec- tomy; 3) dissection above the periosteum and around the lateral aspect of the pedicles and vertebral body; 4) removal of cancellous and cortical bone of the vertebral body; 5) discectomies above and below the osteotomy; and 6) posterior vertebral body wall resection. There is a high risk for pleural and vessel injury during Steps 1, 3, and 4.

In present series, the osteotomy was based on an eggshell and the closing-opening techniques. There were a few advantages to using an eggshell technique in this series. First, the technique did not require the removal of all lateral and anterior cortical bone of the vertebral body. Moreover, only part of a rib on one side was removed. The ribs and remaining cortical bones did not affect the deformity correction rate in Group A. Unlike the usual VCR procedure, the aforementioned Steps 1 and 3 and part of Step 4 were not included in our technique, which can significantly reduce blood loss and the risk of pleural injury. In present series, the mean blood loss was only $960 \pm 120$ $\mathrm{ml}$, and no related complications were observed in Group A; whereas in Group B the mean blood loss was $2600 \pm$ $1600 \mathrm{ml}$, and $37.5 \%$ of the patients experienced one or two complications. Second, because the shape of the affected vertebral body is like a triangle or trapezoid (anterior part of body with lower height), it is easy to remove cancellous bone of the vertebral body of upper- and lower-level discs through the pedicle. Third, the remaining cortical bone can serve as a "bone cage" to maintain the position of the mesh and facilitate the use of a large amount of bone graft on the right side (Fig. 3F).

For severe kyphosis, closing the osteotomy can sometimes not achieve effective correction. At the same time, spinal shortening caused by closure also increases the risk of spinal cord injury. When the kyphotic angle exceeds $40^{\circ}$, it is difficult to obtain a good correction effect with a PSO or an eggshell technique. ${ }^{4}$ When the closing-opening technique is used for correction, the first $30^{\circ}-35^{\circ}$ of the kyphotic angle is corrected by using the closing-wedge technique. Next, the hinge is moved posteriorly to the spinal cord, and the remainder of the requisite angle of osteotomy is corrected by using the opening-wedge technique to avoid spinal cord deformation. At the same time, titanium mesh also effectively prevents the spinal shrinkage caused by excessive cord shortening after the closure. In this series, the correction rate was $68.7 \%$ in Group A, which was not significantly different from that in Group B. Also, no spinal cord injuries occurred during these deformity corrections.

There are several problems that need to be noted during surgery. First, spinal shortening after osteotomy can result in spinal cord shrinkage or injury. We have demonstrated that the degree of shrinkage is correlated with the spinal laminectomy range. ${ }^{6}$ Therefore, during closure of the osteotomy plane, an adequate laminectomy range must be ensured. Generally, in cases of severe kyphosis, the lamina at the osteotomy site and the lamina above and below it should be removed to ensure the safety of the spinal cord. Also, to avoid spinal cord injury, removal of cancellous bone via the pedicle should be performed under the condition that the medial pedicle wall is retained, unless the view during the operation is limited. The posterior vertebral cortex was pushed anteriorly with an L-shaped processor to minimize spinal cord injury during the pro- 


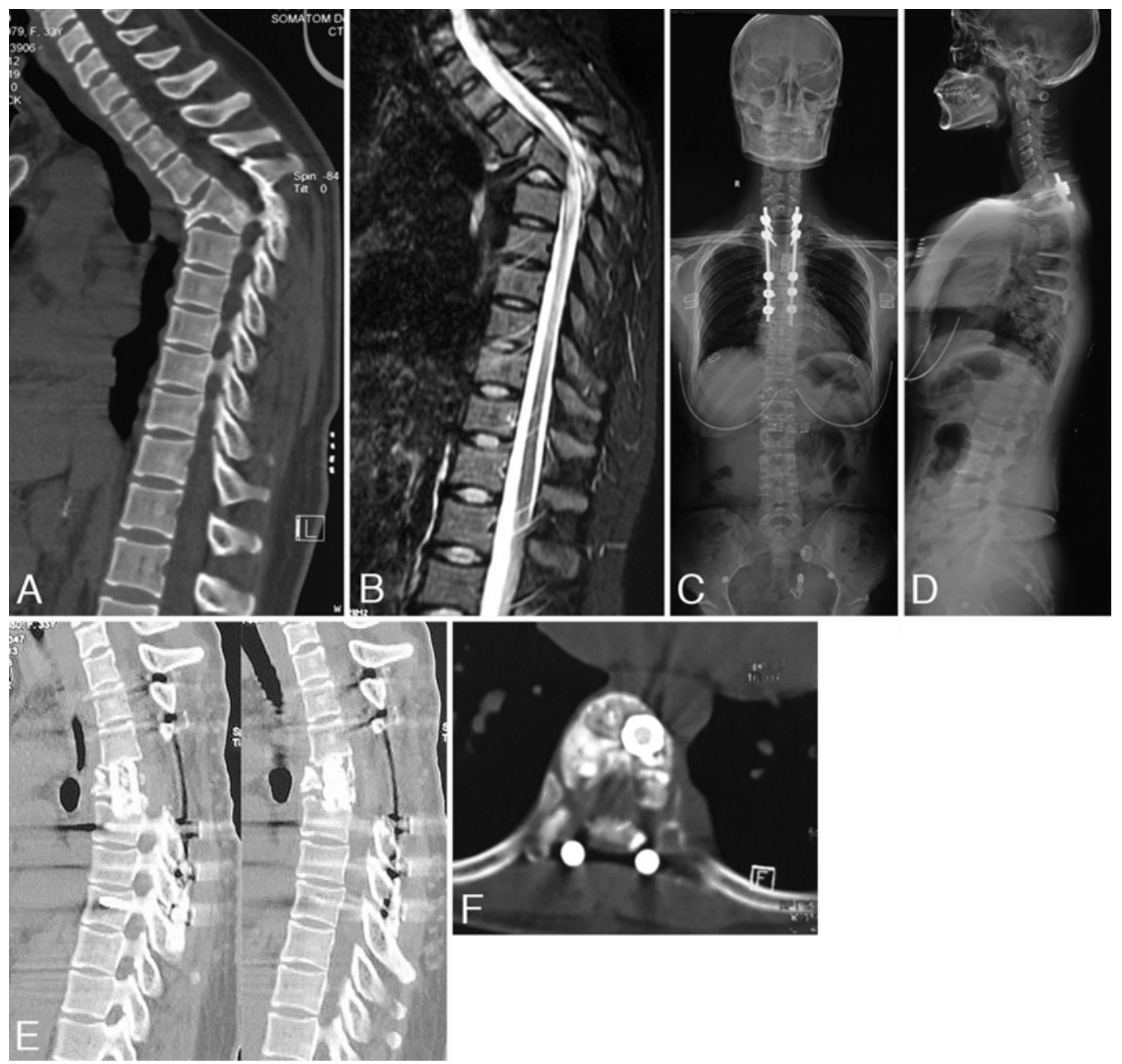

FIG. 3. Thirty-year-old woman with old tuberculosis kyphosis. A and B: Preoperative CT scan and MR image showing vertebral body malunion at T3-5 and a kyphotic angle of $62^{\circ}$. C and D: Two-year postoperative radiographs demonstrating satisfactory correction without loss of correction, an RKA reduced to $21^{\circ}$, and satisfactory bone fusion. $\mathrm{E}$ and $\mathrm{F}$ : CT scans showing solid fusion and the position of the titanium mesh, respectively; note that the anterior and right sides of the cortical bone of the vertebral body and the bilateral ribs were preserved.

cedures we performed. The nerve root at the osteotomy level can affect disc resection and titanium mesh placement. Therefore, the nerves at or above T-12 can be ligated to facilitate the operation and avoid spinal cord injury caused by excessive retraction of the dura and roots. After completion of the osteotomy on one side, a temporary rod should be installed before performing osteotomy on the contralateral side. Moreover, electrophysiological monitoring and wake-up tests should both be conducted during the operation to avoid spinal cord injury.

Second, in patients with old tuberculosis or an old fracture, there was less blood loss when the cancellous bone was removed by bur. For congenital hemivertebra decancellation, a diamond-bit drill and bone wax were used to control blood loss; no other agents were used in this series. Moreover, there is always some venous plexus within the spinal canal close to the medial wall of the pedicles. Therefore, bipolar coagulation should be performed before removing the medial wall of the pedicles to reduce blood loss. Every patient in this study received an autolo- gous blood transfusion, which can effectively reduce blood transfusion complications and the cost of surgery.

Third, it is not necessary to install titanium mesh in the center of the coronal vertebral plane. Placement of the titanium mesh on one side enabled us to put more autograft on the other side to facilitate bone fusion and also to avoid spinal cord injury during installation (Fig. 3F).

\section{Conclusions}

In this small series, an expanded eggshell procedure combined with the closing-opening technique for the treatment of thoracolumbar angular kyphosis resulted in significant reduction of the kyphotic angle, few complications, and good follow-up results. Our primary results show that this technique can be used for thoracic and thoracolumbar angular kyphosis associated with severe back pain and/or neurological deficits. However, a larger series of patients and long-term follow-up are still needed to verify the effectiveness and safety of this method. 


\section{References}

1. Enercan M, Ozturk C, Kahraman S, Sarıer M, Hamzaoglu A, Alanay A: Osteotomies/spinal column resections in adult deformity. Eur Spine J 22 Suppl 2:S254-S264, 2013

2. Hamzaoglu A, Alanay A, Ozturk C, Sarier M, Karadereler $\mathrm{S}$, Ganiyusufoglu K: Posterior vertebral column resection in severe spinal deformities: a total of 102 cases. Spine (Phila Pa 1976) 36:E340-E344, 2011

3. Heining CA: Eggshell procedure, in Luque ER (ed): Segmental Spinal Instrumentation. Thorofare, NJ: Slack, 1984, pp 221-230

4. Kawahara N, Tomita K, Baba H, Kobayashi T, Fujita T, Murakami H: Closing-opening wedge osteotomy to correct angular kyphotic deformity by a single posterior approach. Spine (Phila Pa 1976) 26:391-402, 2001

5. Lenke LG, O'Leary PT, Bridwell KH, Sides BA, Koester LA, Blanke KM: Posterior vertebral column resection for severe pediatric deformity: minimum two-year follow-up of thirtyfive consecutive patients. Spine (Phila Pa 1976) 34:22132221, 2009

6. Liu X, Zheng Y, Li J, Wang Y, Zhang K, Jia L, et al: [The safety range of acute shortening of spinal column after total vertebrectomy.] Chin J Orthop 29:503-507, 2009 (Chinese)

7. Schwab F, Blondel B, Chay E, Demakakos J, Lenke L, Tropiano P, et al: The comprehensive anatomical spinal osteotomy classification. Neurosurgery 74:112-120, 2014

8. Smith-Petersen MN, Larson CB, AuFranc OE: Osteotomy of the spine for correction of flexion deformity in rheumatoid arthritis. J Bone Joint Surg Am 27:1-11, 1945

9. Spiro AS, Rupprecht M, Stenger P, Hoffman M, Kunkel P, Kolb JP, et al: Surgical treatment of severe congenital thoracolumbar kyphosis through a single posterior approach. Bone Joint J 95-B:1527-1532, 2013

10. Suk SI, Chung ER, Kim JH, Kim SS, Lee JS, Choi WK: Posterior vertebral column resection for severe rigid scoliosis. Spine (Phila Pa 1976) 30:1682-1687, 2005

11. Thomasen E: Vertebral osteotomy for correction of kyphosis in ankylosing spondylitis. Clin Orthop Relat Res (194):142152,1985

12. Wang Y, Lenke LG: Vertebral column decancellation for the management of sharp angular spinal deformity. Eur Spine J 20:1703-1710, 2011

\section{Author Contributions}

Conception and design: Liu. Acquisition of data: Liu, Yuan, Tian, Lianlei. Analysis and interpretation of data: Liu. Drafting the article: Liu. Critically revising the article: Zheng. Reviewed submitted version of manuscript: Li. Statistical analysis: Tian.

\section{Correspondence}

Xinyu Liu, MD, Department of Orthopedic Surgery, Qilu Hospital, Shandong University, 107 Wenhua Rd., Jinan, Shandong Province 250012, China. email: newyuliu@ hotmail.com. 